\title{
Best Proximity Points for Relatively $u$-Continuous Mappings in Banach and Hyperconvex Spaces
}

\author{
Jack Markin $^{1}$ and Naseer Shahzad ${ }^{2}$ \\ ${ }^{1} 528$ Rover Boulevard, Los Alamos, NM 87544, USA \\ ${ }^{2}$ Department of Mathematics, King Abdulaziz University, P.O. Box 80203, Jeddah 21589, Saudi Arabia
}

Correspondence should be addressed to Naseer Shahzad; nshahzad@kau.edu.sa

Received 21 May 2013; Accepted 9 August 2013

Academic Editor: Adrian Petrusel

Copyright (C) 2013 J. Markin and N. Shahzad. This is an open access article distributed under the Creative Commons Attribution License, which permits unrestricted use, distribution, and reproduction in any medium, provided the original work is properly cited.

We prove some best proximity point results for relatively $u$-continuous mappings in Banach and hyperconvex metric spaces. Our results generalize and extend some recent results to relatively $u$-continuous mappings and to general spaces.

\section{Introduction}

Let $A, B$ be nonempty subsets of a Banach space $(M,\|\cdot\|)$. In [1], Eldred et al. considered the best proximity point problem for mappings $T: A \cup B \rightarrow A \cup B$ with $T(A) \subset B$ and $T(B) \subset A$ or $T(A) \subset A$ and $T(B) \subset B$, respectively; that is, they sought conditions on the subsets $A, B$, the space $M$, and the mapping $T$ that assure existence of points $x_{0} \in A, y_{0} \in B$ such that

$$
\left\|x_{0}-T\left(x_{0}\right)\right\|=\left\|y_{0}-T\left(y_{0}\right)\right\|=\operatorname{dist}(A, B),
$$

or

$$
\begin{gathered}
x_{0}=T\left(x_{0}\right), \\
y_{0}=T\left(y_{0}\right), \\
\left\|x_{0}-y_{0}\right\|=\operatorname{dist}(A, B),
\end{gathered}
$$

respectively. In solving this problem they considered a new class of mappings.

Definition 1 (see [1]). Let $A, B$ be nonempty subsets of a metric space $(M, d)$. Then a mapping $T: A \cup B \rightarrow A \cup B$ is said to be relatively nonexpansive if

$$
d(T(x), T(y)) \leq d(x, y) \text { for } x \in A, y \in B .
$$

The assumption that a mapping is relatively nonexpansive is weaker than the assumption that it is nonexpansive and does not even imply continuity [1].
Introducing a geometric condition for Banach spaces called proximal normal structure, they obtained the following result.

Theorem 2 (see $[1])$. Let $(A, B)$ be a nonempty weakly compact convex pair in a Banach space $(M,\|\cdot\|)$. Let $T: A \cup B \rightarrow$ $A \cup B$ be a relatively nonexpansive mapping such that $T(A) \subset B$ and $T(B) \subset A$, and suppose that $(A, B)$ has proximal normal structure. Then there exists $\left(x_{0}, y_{0}\right) \in A \times B$ such that

$$
\left\|x_{0}-T\left(x_{0}\right)\right\|=\left\|y_{0}-T\left(y_{0}\right)\right\|=\operatorname{dist}(A, B) .
$$

With the goal of generalizing relatively nonexpansive mappings, Eldred et al. [2] introduced the notion of a relatively $u$-continuous mapping in Banach spaces, which we state here for a metric space.

Definition 3 (see [2]). Let $A, B$ be nonempty subsets of a metric space $(M, d)$. A mapping $T: A \cup B \rightarrow A \cup B$ is said to be relatively $u$-continuous if for each $\epsilon>0$, there exists $\delta>0$ such that $d(T(x), T(y))<\varepsilon+\operatorname{dist}(A, B)$ whenever

$$
d(x, y)<\delta+\operatorname{dist}(A, B), \quad \forall x \in A, y \in B .
$$

Every relatively nonexpansive mapping is relatively $u$ continuous. For an example showing that the converse is not true see [2, Example 2.1].

Eldred et al. [2] were able to extend some of the results of [1] to include the class of relatively $u$-continuous mappings. 
Theorem 4 (see [2]). Let $A, B$ be nonempty compact convex subsets of a strictly convex Banach space $X$, and let $T: A \cup B \rightarrow$ $A \cup B$ be a relatively $u$-continuous mapping such that $T(A) \subset B$ and $T(B) \subset A$. Then there exists

$$
\left(x_{0}, y_{0}\right) \in A \times B
$$

such that $\left\|x_{0}-T\left(x_{0}\right)\right\|=\left\|y_{0}-T\left(y_{0}\right)\right\|=\operatorname{dist}(A, B)$.

In this paper we show that Theorem 4 holds for any Banach space without the assumption of strict convexity as follows.

Theorem 5. Let $(M,\|\cdot\|)$ be a Banach space, and let $A, B$ be nonempty compact convex subsets of $M$. If $T: A \cup B \rightarrow A \cup B$ is relatively $u$-continuous such that $T(A) \subset B$ and $T(B) \subset A$, then there exist points $x \in A$ and $y \in B$ such that $\|x-T(x)\|=$ $\|y-T(y)\|=\operatorname{dist}(A, B)$.

Some interesting best proximity point theorems for various kinds of mappings have been accomplished in [3-8]. Other related results on cyclical mappings can be found in $[9,10]$.

The aim of this paper is to prove some best proximity point results for relatively $u$-continuous mappings in Banach and hyperconvex metric spaces. Our results generalize and extend some recent results to relatively $u$-continuous mappings and to general spaces.

\section{Preliminaries}

Let $A$ and $B$ be nonempty subsets of a metric space $(M, d)$. Define

$$
\begin{gathered}
\operatorname{dist}(A, B)=\inf \{d(x, y): x \in A, y \in B\}, \\
A_{0}=\{x \in A: d(x, y)=\operatorname{dist}(A, B) \text { for some } y \in B\}, \\
B_{0}=\{y \in B: d(x, y)=\operatorname{dist}(A, B) \text { for some } x \in A\} .
\end{gathered}
$$

Definition 6. A metric space $(M, d)$ is hyperconvex if given any family $\left\{x_{\alpha}: \alpha \in I\right\}$ of points in $M$ and any family $\left\{r_{\alpha}\right\}$ of nonnegative real numbers satisfying $d\left(x_{\alpha}, x_{\beta}\right) \leq r_{\alpha}+r_{\beta}$ for all $\alpha, \beta \in I$, then $\cap B\left(x_{\alpha} ; r_{\alpha}\right) \neq \emptyset$, where

$$
B(x ; r)=\{y \in M: d(x, y) \leq r\} .
$$

Definition 7. The admissible subsets of $M$ are sets of the form $\cap B\left(x_{\alpha} ; r_{\alpha}\right)$, that is, the family of ball intersections in $M$. For a subset $X$ of $M, N_{\varepsilon}(X)$ denotes the closed $\varepsilon$-hull of $X$; that is, $N_{\varepsilon}(X)=\{x \in M: \operatorname{dist}(x, X) \leq \varepsilon\}$, where $\operatorname{dist}(x, X)=$ $\inf \{d(x, y): x \in X\}$.

If $X$ is an admissible set, then $N_{\varepsilon}(X)$ is also an admissible set [11]. For recent progress in hyperconvex metric spaces, we refer the reader to [12].

Definition 8 . Let $(M, d)$ be a metric space and $F: M \rightarrow 2^{M}$ a multivalued mapping with nonempty values. Then $F$ is said to be almost lower semicontinuous at a point $x \in M$ if for each $\varepsilon>0$ there is an open neighborhood $U(x)$ of $x$ and a point $z \in M$ such that, for $y \in U(x)$,

$$
B(z ; \varepsilon) \cap F(y) \neq \emptyset .
$$

In establishing existence of best proximity points for relatively $u$-continuous mappings in Banach and hyperconvex spaces, we apply the following continuous selection and fixed point theorems.

Theorem 9 (see [13]). Let $X$ be a paracompact space and $Y$ a normed linear space. Let $F: X \rightarrow 2^{Y}$ be a multivalued mapping with nonempty closed convex values. Then $F$ is an almost lower semicontinuous mapping if and only if for each $\epsilon>0, F$ has a continuous $\epsilon$-approximate selection; that is, a function $f: X \rightarrow Y$ such that for every $x \in X$, $\operatorname{dist}(f(x), F(x))<\epsilon$.

Theorem 10 (see [14]). Let $X$ be a paracompact topological space, $(M, d)$ a hyperconvex metric space, and $F: X \rightarrow 2^{M}$ an almost lower semicontinuous mapping with admissible values. Then $F$ has a continuous selection; that is, there is a continuous mapping $f: X \rightarrow M$ such that $f(x) \in F(x)$ for each $x \in X$.

Theorem 11 (see $[15,16])$. Let $(M, d)$ be a compact hyperconvex metric space and $f: M \rightarrow M$ a continuous mapping. Then $f$ has a fixed point.

\section{Best Proximity Points in Banach Spaces}

The following theorem extends the best proximity point result of Eldred et al. [2, Theorem 3.1] for strictly convex Banach spaces to any Banach space.

Proof of Theorem 5. Since $A, B$ are compact convex subsets, $A_{0}, B_{0}$ are nonempty compact convex subsets. By [2, Proposition 3.1] $T\left(A_{0}\right) \subset B_{0}$ and $T\left(B_{0}\right) \subset A_{0}$.

By $u$-continuity of $T$, for any $x \in A, y \in B$ such that $\|x-y\|=\operatorname{dist}(A, B)$ and any positive integer $n$ there is a $\delta_{n}>0$ and a neighborhood of $x$ in $A_{0}$ defined as

$$
U\left(x, \delta_{n}\right)=\left\{u \in A_{0}:\|u-x\|<\delta_{n}\right\},
$$

such that $u \in U\left(x, \delta_{n}\right)$ implies that

$$
\|T(u)-T(y)\| \leq\left(\frac{1}{n}\right)+\operatorname{dist}(A, B) .
$$

For each positive integer $n$, define a multivalued mapping $F_{n}: A_{0} \rightarrow 2^{A_{0}}$ by

$$
F_{n}(v)=B\left(T(v) ;\left(\frac{1}{n}\right)+\operatorname{dist}(A, B)\right) \cap A_{0},
$$

for $v \in A_{0}$. Since $T(v) \in B_{0}, F_{n}(v)$ is nonempty. As the intersection of closed convex sets, each $F_{n}(v)$ is also closed convex.

By (11), $T(y) \in F_{n}(u)$ for each $u \in U\left(x, \delta_{n}\right)$, which implies that the mapping $F_{n}$ is almost lower semicontinuous. By the approximate selection result of Deutsch et al. [13] 
(see Theorem 9), for any $\alpha>0, F_{n}$ has a continuous $\alpha$ approximate selection; that is, there is a continuous $f_{n}$ : $A_{0} \rightarrow A_{0}$ such that $\operatorname{dist}\left(f_{n}(v), F_{n}(v)\right) \leq \alpha$. Choosing $\alpha=$ $1 / n$, by the definition of $F_{n}$ the selection $f_{n}$ satisfies

$$
\begin{array}{r}
\left\|T(v)-f_{n}(v)\right\| \leq\left(\frac{2}{n}\right)+\operatorname{dist}(A, B), \\
\text { for } v \in A_{0} .
\end{array}
$$

Since the mapping $f_{n}$ is continuous and $A_{0}$ is a compact convex subset of a Banach space, the Schauder fixed point theorem implies that $f_{n}$ has a fixed point $x_{n}$; that is, there is a point $x_{n} \in A_{0}$ such that $x_{n}=f_{n}\left(x_{n}\right)$.

By (13), $\left\|T\left(x_{n}\right)-x_{n}\right\| \rightarrow \operatorname{dist}(A, B)$, and by compactness of $A_{0}$ and $B_{0}$, we can assume that $x_{n} \rightarrow x \in A_{0}$ and $T\left(x_{n}\right) \rightarrow$ $p \in B_{0}$. Therefore, $\|x-p\|=\operatorname{dist}(A, B)$, and by $u$-continuity of $T,\left\|T\left(x_{n}\right)-T(p)\right\| \rightarrow \operatorname{dist}(A, B)$. It follows that

$$
\begin{aligned}
\operatorname{dist}(A, B) & \leq\|p-T(p)\| \\
& \leq\left\|p-T\left(x_{n}\right)\right\|+\left\|T\left(x_{n}\right)-T(p)\right\| \\
& \longrightarrow \operatorname{dist}(A, B),
\end{aligned}
$$

which implies that $\|p-T(p)\|=\operatorname{dist}(A, B)$.

The following proposition follows by a slight change in the proof in [2, Proposition 3.1].

Proposition 12. Let $A, B$ be nonempty subsets of a normed linear space $M$, and let $T: A \cup B \rightarrow A \cup B$ be a relatively $u$ continuous mapping such that $T(A) \subset A$ and $T(B) \subset B$. Then $T\left(A_{0}\right) \subset A_{0}$ and $T\left(B_{0}\right) \subset B_{0}$.

Proposition 13 (see [17]). Let $(M,\|\cdot\|)$ be a strictly convex Banach space, A a nonempty compact convex subset of $M$, and $B$ a nonempty closed convex subset of $M$. Let $\left\{x_{n}\right\}$ be a sequence in $A$ and $y \in B$. If

$$
\left\|x_{n}-y\right\| \longrightarrow \operatorname{dist}(A, B), \text { then } x_{n} \longrightarrow P_{A}(y) .
$$

In [1] a best proximity result was given for relatively nonexpansive mappings in a uniformly convex space. The following result is a version of that result for relatively $u$ continuous mappings in a strictly convex space.

Theorem 14. Let $(M,\|\cdot\|)$ be a strictly convex Banach space, and let $A, B$ be compact convex subsets of $M$. If $T: A \cup B \rightarrow$ $A \cup B$ is relatively $u$-continuous such that $T(A) \subset A$ and $T(B) \subset$ $B$, then there exist points $x_{0} \in A$ and $y_{0} \in B$ such that $x_{0}=$ $T\left(x_{0}\right), y_{0}=T\left(y_{0}\right)$ and $\left\|x_{0}-y_{0}\right\|=\operatorname{dist}(A, B)$.

Proof. Since $A, B$ are compact convex sets, $A_{0}$ and $B_{0}$ are nonempty compact convex sets, and by Proposition 12, $T\left(A_{0}\right) \subset A_{0}$ and $T\left(B_{0}\right) \subset B_{0}$.

By $u$-continuity of $T$, for any positive integer $n$ there is a $\delta_{n}>0$ such that

$$
\|x-y\| \leq \delta_{n}+\operatorname{dist}(A, B)
$$

implies that $\|T(x)-T(y)\|<(1 / n)+\operatorname{dist}(A, B)$, for $x \in A$ and $y \in B$. For $x \in A_{0}$ define $U\left(x, \delta_{n}\right)=\left\{u \in A_{0}:\|u-x\|<\delta_{n}\right\}$, and let $y=P_{B}(x)$. Then $u \in U\left(x, \delta_{n}\right)$ implies that

$$
\|u-y\| \leq\|u-x\|+\|x-y\|<\delta_{n}+\operatorname{dist}(A, B),
$$

and therefore, by $u$-continuity of $T$,

$$
\|T(u)-T(y)\| \leq\left(\frac{1}{n}\right)+\operatorname{dist}(A, B) .
$$
by

For each positive integer $n$, define a map $F_{n}: A_{0} \rightarrow 2^{B_{0}}$

$$
F_{n}(v)=B\left(T(v) ;\left(\frac{1}{n}\right)+\operatorname{dist}(A, B)\right) \cap B_{0},
$$

for $v \in A_{0}$. As the intersection of closed convex sets, $F_{n}(v)$ is also closed convex. By (18), $T(y) \in F_{n}(u)$ for $u \in U\left(x, \delta_{n}\right)$, which implies that $F_{n}(u)$ is nonempty and also that $F_{n}$ is an almost lower semicontinuous mapping.

Since $M$ is a normed linear space, by Theorem 9 for any $\alpha>0, F_{n}$ has a continuous $\alpha$-approximate selection; that is, there is a continuous $f_{n}: A_{0} \rightarrow B_{0}$ such that $\operatorname{dist}\left(f_{n}(v), F_{n}(v)\right) \leq \alpha$, for $v \in A_{0}$. Choosing $\alpha=1 / n$, by the definition of $F_{n}$ the selection $f_{n}$ satisfies

$$
\left\|T(v)-f_{n}(v)\right\| \leq\left(\frac{2}{n}\right)+\operatorname{dist}(A, B),
$$

for $v \in A_{0}$.

Consider the metric projection operator $P_{A}: M \rightarrow A$. Since $f_{n}\left(A_{0}\right) \subset B_{0}$ and $P_{A}\left(B_{0}\right) \subset A_{0}$, the map $P_{A} \circ f_{n}$ sends $A_{0}$ into $A_{0}$. Since $P_{A} \circ f_{n}$ is continuous and $A_{0}$ is compact and convex, by the Schauder fixed point theorem there is a fixed point $x_{n}=P_{A} \circ f_{n}\left(x_{n}\right) \in A_{0}$. Let $y_{n}=f_{n}\left(x_{n}\right) \in B_{0}$, and assume by compactness that $x_{n}, y_{n}$ converge to $x_{0} \in A_{0}$, $y_{0} \in B_{0}$, respectively. By continuity of $P_{A}, x_{0}=P_{A}\left(y_{0}\right)$.

By definition of the map $f_{n},\left\|T\left(x_{n}\right)-y_{n}\right\| \leq(2 / n)+$ $\operatorname{dist}(A, B)$, and since $y_{n} \rightarrow y_{0}$ we have

$$
\begin{aligned}
& \left\|T\left(x_{n}\right)-y_{0}\right\| \\
& \quad \leq\left\|T\left(x_{n}\right)-y_{n}\right\|+\left\|y_{n}-y_{0}\right\| \longrightarrow \operatorname{dist}(A, B) .
\end{aligned}
$$

Therefore, by Proposition 13,

$$
T\left(x_{n}\right) \longrightarrow P_{A}\left(y_{0}\right) .
$$
that

By $u$-continuity of $T$, for any $\epsilon>0$ there is a $\delta>0$ such

$$
\begin{aligned}
& \left\|T\left(x_{n}\right)-T\left(y_{0}\right)\right\| \\
& \quad<\epsilon+\operatorname{dist}(A, B) \text { provided }\left\|x_{n}-y_{0}\right\|<\delta+\operatorname{dist}(A, B) .
\end{aligned}
$$

Since $x_{n} \rightarrow x_{0}$, choose $n$ sufficiently large that $\left\|x_{n}-x_{0}\right\|<\delta$. Then

$$
\begin{aligned}
& \left\|x_{n}-y_{0}\right\| \\
& \quad \leq\left\|x_{n}-x_{0}\right\|+\left\|x_{0}-y_{0}\right\|<\delta+\operatorname{dist}(A, B),
\end{aligned}
$$


which implies that

$$
\begin{aligned}
& \operatorname{dist}(A, B) \\
& \quad \leq\left\|T\left(x_{n}\right)-T\left(y_{0}\right)\right\|<\epsilon+\operatorname{dist}(A, B) .
\end{aligned}
$$

Since $\epsilon$ is arbitrary,

$$
\left\|T\left(x_{n}\right)-T\left(y_{0}\right)\right\| \longrightarrow \operatorname{dist}(A, B) .
$$

Therefore, by Proposition 13,

$$
T\left(x_{n}\right) \longrightarrow P_{A}\left(T\left(y_{0}\right)\right) .
$$

By the relations (22) and (27), $T\left(x_{n}\right)$ converges to both $P_{A}\left(y_{0}\right)$ and $P_{A}\left(T\left(y_{0}\right)\right)$. Therefore, $x_{0}=P_{A}\left(y_{0}\right)=P_{A}\left(T\left(y_{0}\right)\right)$. Since $y_{0}, T\left(y_{0}\right) \in B_{0},\left\|x_{0}-y_{0}\right\|=\left\|x_{0}-T\left(y_{0}\right)\right\|=\operatorname{dist}(A, B)$, and by strict convexity of $M, y_{0}=T\left(y_{0}\right)$.

Since $\left\|x_{0}-y_{0}\right\|=\operatorname{dist}(A, B)$, we have by $u$-continuity of $T$ that $\left\|T\left(x_{0}\right)-T\left(y_{0}\right)\right\|=\operatorname{dist}(A, B)$. Therefore, $T\left(x_{0}\right)=$ $P_{A}\left(T\left(y_{0}\right)\right)$, and since $x_{0}=P_{A}\left(T\left(y_{0}\right)\right)$, this implies that $x_{0}=$ $T\left(x_{0}\right)$.

\section{Best Proximity Points in Hyperconvex Spaces}

The following is a best proximity point result for relatively $u$-continuous mappings in hyperconvex metric spaces. Best proximity point/pair results were obtained in the setting of hyperconvex spaces by some authors in [18-21].

Theorem 15. Let $A, B$ be admissible subsets of a hyperconvex metric space $(M, d)$, let $A_{0}$ be a compact subset of $M$ and let $T: A \cup B \rightarrow A \cup B$ be a relatively $u$-continuous mapping such that $T(A) \subset B$, and $T(B) \subset A$. Then there is an $x_{0} \in A_{0}$ such that $d\left(x_{0}, T\left(x_{0}\right)\right)=\operatorname{dist}(A, B)$.

Proof. By a result of Kirk et al. [18], the sets $A_{0}$ and $B_{0}$ are nonempty and hyperconvex. For $x \in A_{0}$, choose $y \in B_{0}$ such that $d(x, y)=\operatorname{dist}(A, B)$. Then, by $u$-continuity of $T$, for any $\varepsilon>0$ there is a $\delta>0$ such that for $u \in A, v \in B$,

$$
\begin{aligned}
& d(u, v)<\delta+\operatorname{dist}(A, B) \\
& \text { implies that } d(T(u), T(v))<\varepsilon+\operatorname{dist}(A, B) .
\end{aligned}
$$

It follows that $d(T(x), T(y))=\operatorname{dist}(A, B)$. This implies that $T(x) \in B_{0}$ for $x \in A_{0}$.

Define an open neighborhood of $x$ in $A_{0}$ by $U(x)=\{u \in$ $\left.A_{0}: d(u, x)<\delta\right\}$.

Then $u \in U(x)$ implies that

$$
d(u, y) \leq d(u, x)+d(x, y)<\delta+\operatorname{dist}(A, B),
$$

and therefore, by $u$-continuity of $T$,

$$
d(T(u), T(y))<\varepsilon+\operatorname{dist}(A, B) .
$$

Define a multivalued $F: A_{0} \rightarrow 2^{A_{0}}$ by

$$
F(v)=B(T(v) ; \operatorname{dist}(A, B)) \cap A,
$$

for $v \in A_{0}$. Since $T(v) \in B_{0}$ for $v \in A_{0}, F(v)$ is a nonempty subset of $A_{0}$, and since $A$ is admissible, $F(v)$ is also admissible.

We show that $F$ is almost lower semicontinuous by establishing that $B(T(y) ; \varepsilon) \cap F(u) \neq \emptyset$ for $u \in U(x)$. By (30) and the hyperconvexity of $M$, for $u \in U(x)$,

$$
B(T(y) ; \varepsilon) \cap B(T(u) ; \operatorname{dist}(A, B)) \neq \emptyset .
$$

Since $T(u) \in B_{0}$, we have

$$
B(T(u) ; \operatorname{dist}(A, B)) \cap A \neq \emptyset .
$$

Any point $p$ in the intersection (33) is in $A_{0}$ since $d(p, T(u))=$ $\operatorname{dist}(A, B)$. Therefore,

$$
B(T(u) ; \operatorname{dist}(A, B)) \cap A \subset A_{0} .
$$

By (32), (33), and the fact that $T(y) \in A_{0}$, the sets $B(T(y) ; \varepsilon)$, $B(T(u)$; dist $(A, B))$, and $A$ have pairwise nonempty intersection. Since all of these sets are ball intersections, the hyperconvexity of the space $M$ implies that

$$
B(T(y) ; \varepsilon) \cap B(T(u) ; \operatorname{dist}(A, B)) \cap A \neq \emptyset .
$$

Further, by (34), the intersection in (35) is contained in $A_{0}$. It follows from (35) that $B(T(y) ; \varepsilon) \cap F(u) \neq \emptyset$ for $u \in U(x)$. This implies that the mapping $F$ is almost lower semicontinuous.

By the selection theorem in Markin [14] (see Theorem 10), an almost lower semicontinuous mapping on a hyperconvex space with nonempty admissible values has a continuous selection; that is, there is a continuous $f: A_{0} \rightarrow A_{0}$ such that $f(x) \in F(x)$ for $x \in A_{0}$. By Theorem 11, a continuous selfmapping on a compact hyperconvex space has a fixed point. Therefore, there is a $w \in A_{0}$ such that $w=f(w) \in F(w)$. By the definition of $F$,

$$
d(w, T(w))=\operatorname{dist}(A, B) .
$$

\section{Acknowledgment}

The authors thank the referees for providing useful comments and suggestions that improved the paper.

\section{References}

[1] A. A. Eldred, W. A. Kirk, and P. Veeramani, "Proximal normal structure and relatively nonexpansive mappings," Studia Mathematica, vol. 171, no. 3, pp. 283-293, 2005.

[2] A. A. Eldred, V. S. Raj, and P. Veeramani, "On best proximity pair theorems for relatively u-continuous mappings," Nonlinear Analysis: Theory, Methods \& Applications, vol. 74, no. 12, pp. 3870-3875, 2011.

[3] M. A. Al-Thagafi and N. Shahzad, "Convergence and existence results for best proximity points," Nonlinear Analysis: Theory, Methods \& Applications, vol. 70, no. 10, pp. 3665-3671, 2009.

[4] S. S. Basha and N. Shahzad, "Best proximity point theorems for generalized proximal contractions," Fixed Point Theory and Applications, vol. 2012, article 42, 9 pages, 2012.

[5] S. S. Basha, N. Shahzad, and R. Jeyaraj, "Best proximity points: approximation and optimization," Optimization Letters, vol. 7, no. 1, pp. 145-155, 2013. 
[6] S. S. Basha, N. Shahzad, and R. Jeyaraj, "Best proximity point theorems for reckoning optimal approximate solutions," Fixed Point Theory and Applications, vol. 2012, article 202, 9 pages, 2012.

[7] S. S. Basha, N. Shahzad, and R. Jeyaraj, "Common best proximity points: global optimal solutions," Journal of Optimization Theory and Applications, vol. 148, no. 1, pp. 69-78, 2011.

[8] M. Gabeleh and N. Shahzad, "Existence and convergence theorems of best proximity points," Journal of Applied Mathematics, vol. 2013, Article ID 101439, 6 pages, 2013.

[9] W. A. Kirk, P. S. Srinivasan, and P. Veeramani, "Fixed points for mappings satisfying cyclical contractive conditions," Fixed Point Theory, vol. 4, no. 1, pp. 79-89, 2003.

[10] S. Karpagam and S. Agrawal, "Existence of best proximity points of p-cyclic contractions," Fixed Point Theory, vol. 13, no. 1, pp. 99-105, 2012.

[11] R. Sine, "Hyperconvexity and approximate fixed points," Nonlinear Analysis: Theory, Methods \& Applications, vol. 13, no. 7, pp. 863-869, 1989.

[12] R. Espínola and P. Lorenzo, "Metric fixed point theory on hyperconvex spaces: recent progress," Arabian Journal of Mathematics, vol. 1, no. 4, pp. 439-463, 2012.

[13] F. Deutsch, V. Indumathi, and K. Schnatz, "Lower semicontinuity, almost lower semicontinuity, and continuous selections for set-valued mappings," Journal of Approximation Theory, vol. 53, no. 3, pp. 266-294, 1988.

[14] J. T. Markin, "A selection theorem for quasi-lower semicontinuous mappings in hyperconvex spaces," Journal of Mathematical Analysis and Applications, vol. 321, no. 2, pp. 862-866, 2006.

[15] M. A. Khamsi, "KKM and Ky Fan theorems in hyperconvex metric spaces," Journal of Mathematical Analysis and Applications, vol. 204, no. 1, pp. 298-306, 1996.

[16] W. A. Kirk and S. S. Shin, "Fixed point theorems in hyperconvex spaces," Houston Journal of Mathematics, vol. 23, no. 1, pp. 175188, 1997.

[17] V. S. Raj and P. Veeramani, "Best proximity pair theorems for relatively nonexpansive mappings," Applied General Topology, vol. 10, no. 1, pp. 21-28, 2009.

[18] W. A. Kirk, S. Reich, and P. Veeramani, "Proximinal retracts and best proximity pair theorems," Numerical Functional Analysis and Optimization, vol. 24, no. 7-8, pp. 851-862, 2003.

[19] J. Markin and N. Shahzad, "Best approximation theorems for nonexpansive and condensing mappings in hyperconvex spaces," Nonlinear Analysis: Theory, Methods \& Applications, vol. 70, no. 6, pp. 2435-2441, 2009.

[20] A. Abkar and M. Gabeleh, "Results on the existence and convergence of best proximity points," Fixed Point Theory and Applications, vol. 2010, Article ID 386037, 10 pages, 2010.

[21] A. Amini-Harandi, A. P. Farajzadeh, D. O'Regan, and R. P. Agarwal, "Coincidence point, best approximation, and best proximity theorems for condensing set-valued maps in hyperconvex metric spaces," Fixed Point Theory and Applications, vol. 2008, Article ID 543154, 8 pages, 2008. 


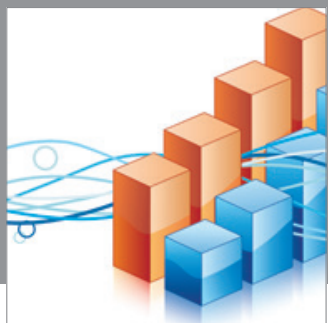

Advances in

Operations Research

mansans

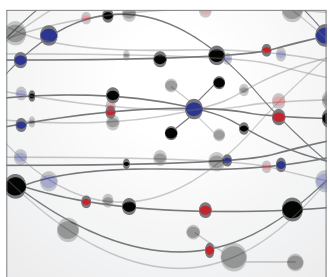

The Scientific World Journal
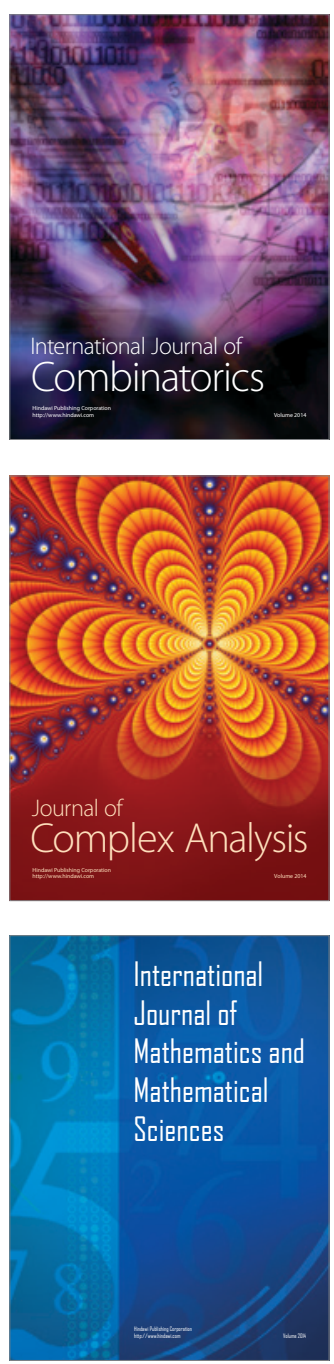
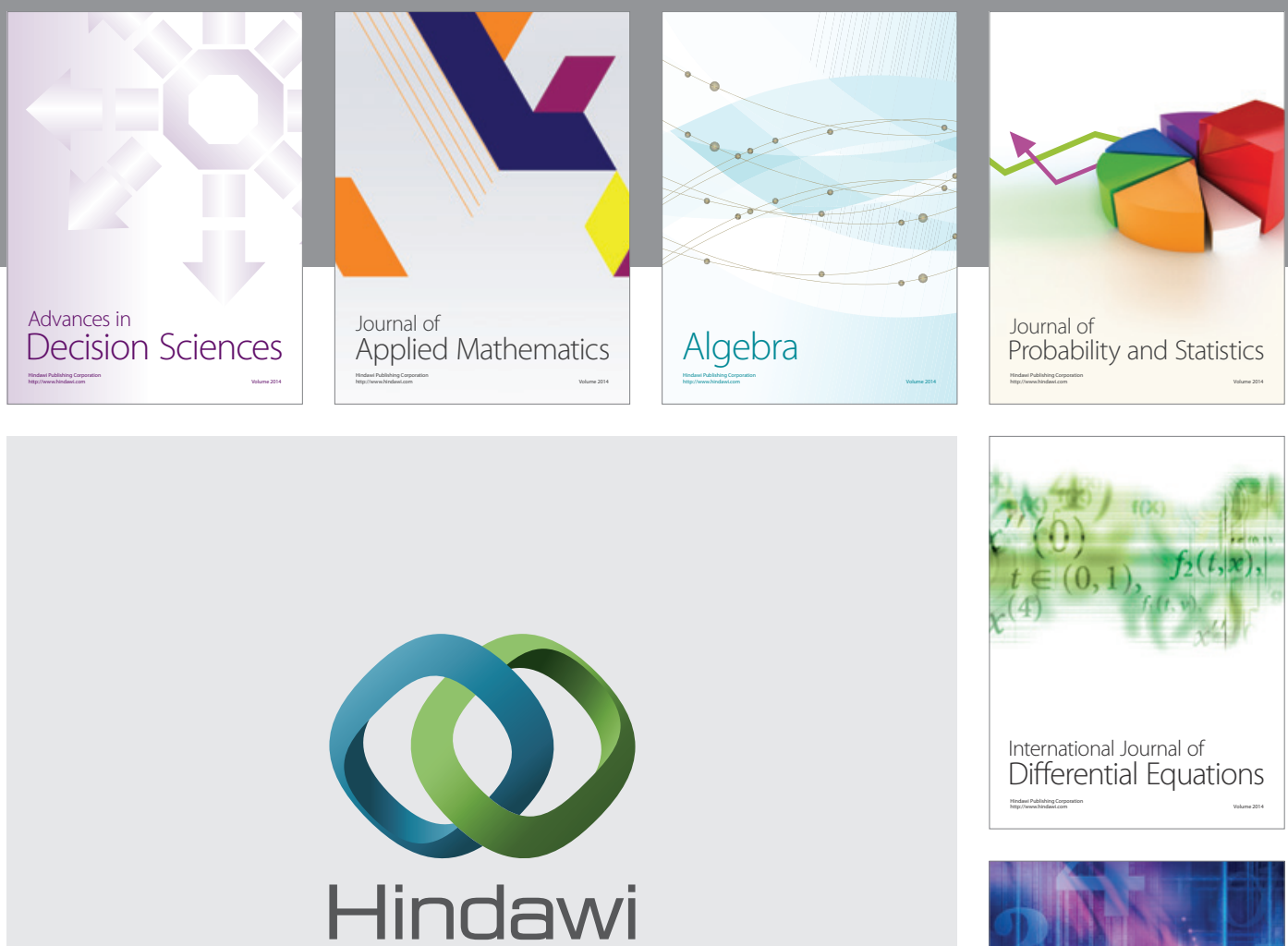

Submit your manuscripts at http://www.hindawi.com
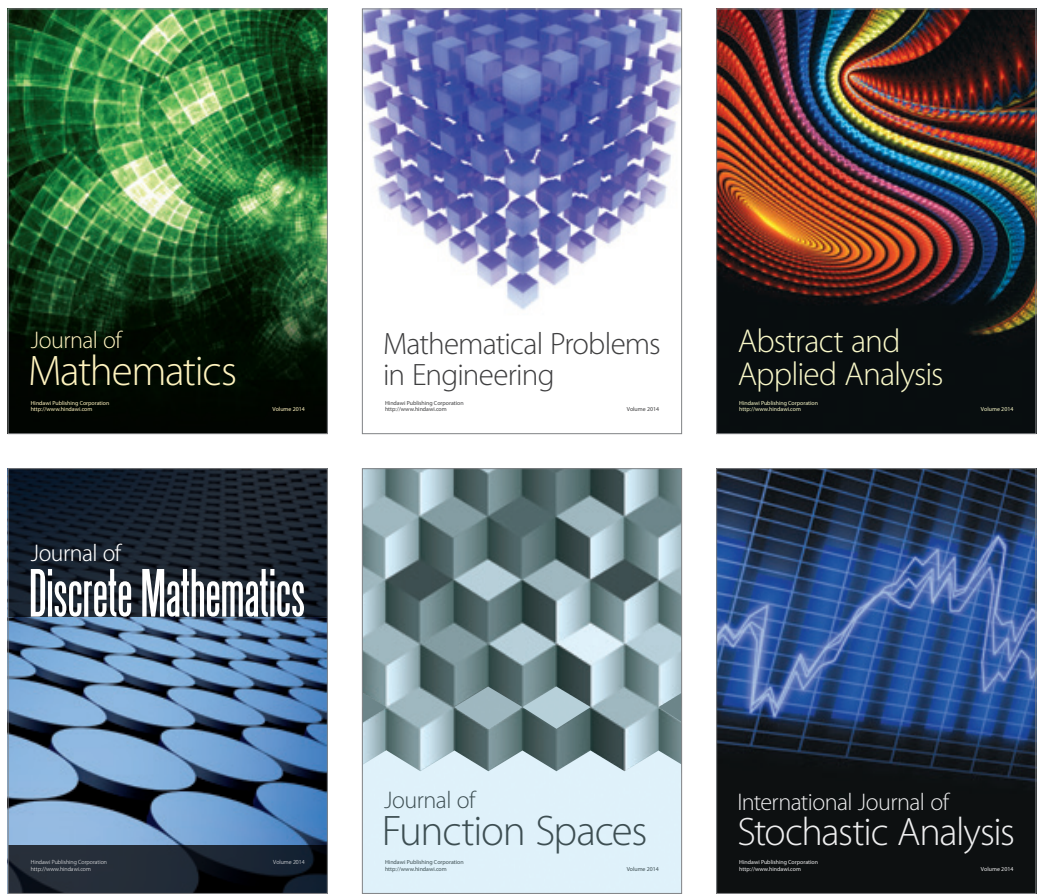

Journal of

Function Spaces

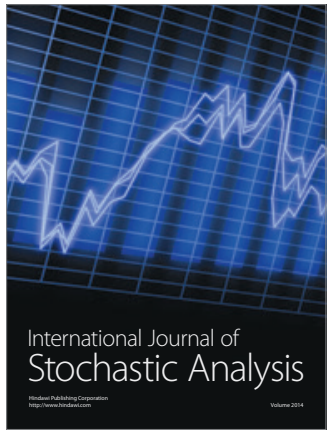

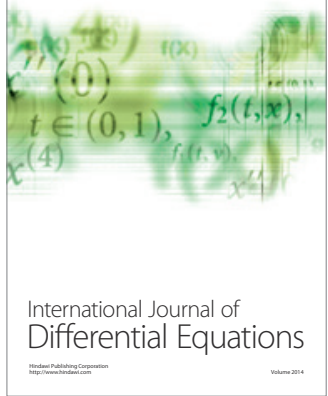
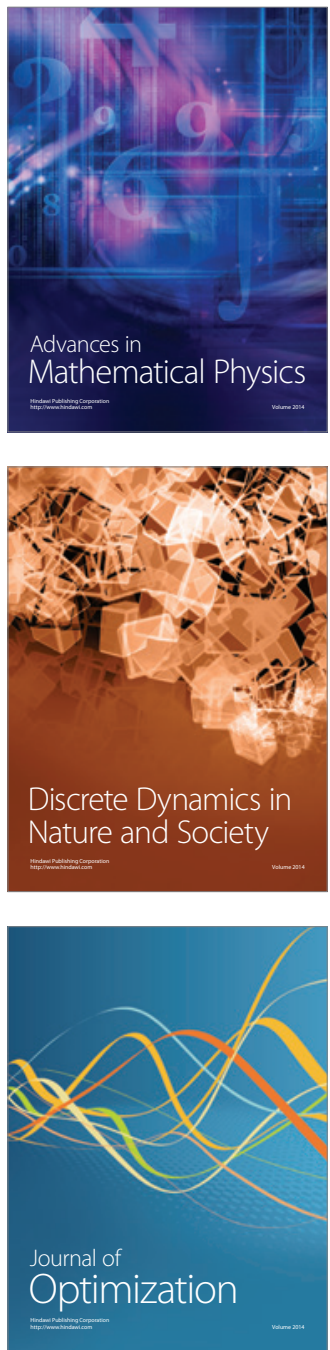